\title{
Synthetic Novel 1, 4- Dihydropyridine Derivatives Act as Potential Hepatoprotective Agent against $\mathrm{CCl}_{4}$ Induced Rat Hepatocytes
}

\author{
Asish Bhaumik, Gelli Venkata Chaitanya Reddy, Shaik Yasin Pasha, Shaik Shareef and Rekkala Nagababu \\ Department of Pharmaceutical Chemistry, Teja College of Pharmacy Kodad, Nalgonda-508206, Telangana State, India
}

\begin{abstract}
The objective of the present work was the synthesis of 1-[5-acetyl-4 (4-substituted phenyl)-2, 6-dimethyl-1,4-dihydroxypyridine-3-yl]-ethan-1-one and evaluation of in vivo hepatoprotective activity. Based on this a new series of compound had been planned to synthesize by reacting acetyl acetone with various aromatic aldehydes in the presence of ammonium acetate. The synthesized compounds were characterized by IR, NMR, and Mass spectroscopy. The in-vivo Hepatoprotective activity was carried out by using albino rats. The results displayed that the elevated levels of SGOT, SGPT, ALP and Serum bilirubin were mainly due to $\mathrm{CCl}_{4}$ intoxication, reduced significantly $\left({ }^{*} P<0.05\right)$ in rats, after treatment with synthesized compounds. Treatment with a synthesized compound at a dose of $250 \mathrm{mg} / \mathrm{kg}$ b.w. decreased the SGOT, SGPT, ALP, Serum bilirubin levels by $6.23 \% \mathrm{~ns}$ (non significantly), $28.96 \%$, $8.81 \%$, and $11.11 \% \mathrm{~ns}$ (non significantly) respectively, while a higher dose of $500 \mathrm{mg} / \mathrm{kg} \mathrm{b}$. wt. was more effective, causing a reduction of $25.02 \%, 47.65 \%, 24.09 \%$ and $27.35 \%$. Silymarin was used as standard drug showed a reduction of 55.09\%, 68.98\%, 57.46\% and 35.04\% receiving $\mathrm{CCl}_{4}$ alone. So depending upon the experimental data it was confirmed that the biochemical parameters of the group treated with compounds were significantly lower than the $\mathrm{CCl}_{4}$ treated group. Moreover the treatment with the synthesized compounds significantly reduced the previously raised levels of AST, ALT, ALP and bilirubin in hepatotoxic rats. Histopathological investigation displayed that at both doses ( $250 \mathrm{mg} / \mathrm{kg}$ b.w. and $500 \mathrm{mg} / \mathrm{kg}$ b.w.) the synthesized compounds were possessed moderate to good hepatoprotective activity, but at $500 \mathrm{mg} / \mathrm{kg}$ b.w. executed excellent hepatoprotective activity against CCl4 induced damaged hepatocytes.
\end{abstract}

Key words: IR, NMR, Hepatocyte, SGOT, SGPT, SALP.

\section{Introduction}

Dihydropyridine is a molecule based upon pyridine, and the parent of a class of molecules that have been semi-saturated with two substituents replacing one double bond. They are particularly well known in pharmacology as L-type calcium channel blockers, used in the treatment of hypertension. Compared with certain other L-type calcium channel blockers (for example those of the phenylalkylamine class such as Verapamil) which have significant action at the heart, they are relatively vascular selective in their mechanism of action in lowering blood pressure [1].

The Hantzsch pyridine synthesis or Hantzsch dihydropyridine synthesis (scheme 1) is a

Corresponding author: Asish Bhaumik, M. Pharm., assistant professor, research field: medicinal chemistry. E-mail: bhaumik.asish@gmail.com. multi-component organic reaction between an aldehyde such as formaldehyde, 2 equivalents of a $\beta$-keto ester such as ethyl acetoacetate and a nitrogen donor such as ammonium acetate or ammonia [2]. The initial reaction product is a dihydropyridine which can be oxidized in a subsequent step to a pyridine. The driving force for this second reaction step is aromatization. This reaction was reported in 1881 by Arthur Rudolf Hantzsch. A 1, 4-dihydropyridine dicarboxylate is also called a 1, 4-DHP compound or a Hantzsch compound. These compounds are an important class of calcium channel blockers and as such commercialized in for instance nifedipine, amlodipine or nimodipine. The reaction has been demonstrated to proceed in water as reaction solvent and with direct aromatization by ferric chloride, Manganese Dioxide or potassium permanganate in a one-pot synthesis[3]. 


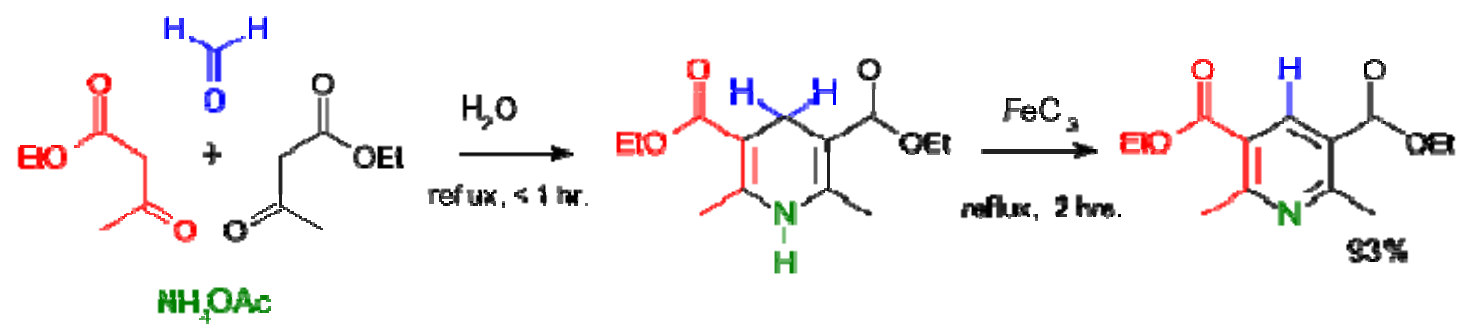

Scheme 1 Hantzsch pyridine synthesis

The Hantzsch dihydropyridine synthesis is found to benefit from microwave chemistry [4]. Calcium channel blockers (CCB), calcium channel antagonists or calcium antagonists [5] are several medications that disrupt the movement of calcium $(\mathrm{Ca} 2+)$ through calcium channels [6] Calcium channel blockers are used as antihypertensive drugs, i.e., as medications to decrease blood pressure in patients with hypertension. CCBs are particularly effective against large vessel stiffness, one of the common causes of elevated systolic blood pressure in elderly patients [7] Calcium channel blockers are also frequently used to alter heart rate, to prevent cerebral vasospasm, and to reduce chest pain caused by angina pectoris. N-type, L-type, and T-type voltage-dependent calcium channels are present in the zona glomerulosa of the human adrenal, and CCBs can directly influence the biosynthesis of aldosterone in adrenocortical cells, with consequent impact on the clinical treatment of hypertension with these agents [8].

DHP (Dihydropyridine) calcium channel blockers are derived from the molecule dihydropyridine and often used to reduce systemic vascular resistance and arterial pressure. Sometimes when they are used to treat angina, the vasodilation and hypotension can lead to reflex tachycardia, which can be detrimental for patients with ischemic symptoms because of the resulting increase in myocardial oxygen demand. Dihydropyridine calcium channel blockers can worsen proteinuria in patients with nephropathy [9]. Moreover 4-phenyl substituted 3,5-diacetyl-1,4-dihydropyridines Showed cytotoxic activity against HSC-2 (human oral suamous carcinoma) cells $[10,11]$.
The objective of the present work is the synthesis of 1-[5-acetyl-4 (4-substituted phenyl)-2, 6-dimethyl-1, 4-dihydroxypyridine-3-yl]-ethan-1-one and evaluation of in vivo hepatoprotective activity. Based on this a new series of compound have been planned to synthesize by reacting acetyl acetone with various aromatic aldehydes in the presence of ammonium acetate which involved Knoevenagel Condensation and Michael Addition reaction.

\section{Materials and Methods}

The all chemicals used for the synthesis were of laboratory grade and analytical grade. The melting points of newly synthesized 1,4-dihydrpyridine compounds were determined by open capillary method. The IR spectra of synthesized compounds were recorded by ABB Bomen FT-IR spectrometer MB 104 IR spectra recorder with $\mathrm{KBr}$ pellets. The $\mathrm{H}^{1}$-NMR spectra of synthesized compounds were recorded by BRUKER NMR spectrometer in $\mathrm{CDCl}_{3}$. The Mass spectra of synthesized compounds were recorded by JEOL GCmate. The purification of newly synthesiszed compounds were done by TLC method.TLC plates are pre-coated silica gel(HF254-200 mesh) aluminium plate using ethyl acetate and n-hexane as an solvent system and spots were visualized under U.V chamber. The IR, $\mathrm{H}^{1}$-NMR and Mass spectra were assigned to elucidate the structure of synthesized compounds (B1-B6).

\subsection{Hepatotoxin}

In the present study the in-vivo hepatoprotective activity was evaluated by $\mathrm{CCl} 4$ induced hepatotoxicity 
model in rats. CCl4 was given subsequently with or without standard as well as test drug in control, test and standard group of animal by maintaining the normal diet during the study period of seven days. The blood was collected from retro-orbital route on the 8th day and the biochemical tests were performed to evaluate the hepatoprotective potential of the drug.

\subsection{Experimental Animals}

White male albino rats weighing about 200-250 g were used. They were obtained from the animal house of C.L. Baid Metha College of Pharmacy, Chennai. They were kept under observation for about 7 days before the onset of the experiment to exclude any intercurrent infection, had free access to normal diet and water. The animals were housed in plastic well aerated cages at normal atmospheric temperature $(25 \pm$
$5{ }^{\circ} \mathrm{C}$ ) and normal 12- hour light/dark cycle under hygienic conditions.

2.3 General Procedure for the Synthesis of Target Compounds (Scheme 2) [12, 13]

To a stirred mixture of aromatic aldehydes $(0.318 \mathrm{~g})$ and acetyl acetone $(0.696 \mathrm{~g})$, ammonium acetate $(0.231$ g) was added; the reaction mixture was homogenized by stirring to a viscous liquid. The progress of the reaction was monitored by TLC. The mobile phase for the synthesized compounds B1, B2, B3, B4, B5 and B6 was ethyl acetate and $n$-hexane in the ratio of $6: 4$. After completion of reaction a small amount of ethanol was added to the viscous liquid and stirred for $5 \mathrm{~min}$. Ice cold water was added to the mixture, the solid thus obtained was filtered. The crude product was purified by crystallization from ethanol: water (95:5) mixture.

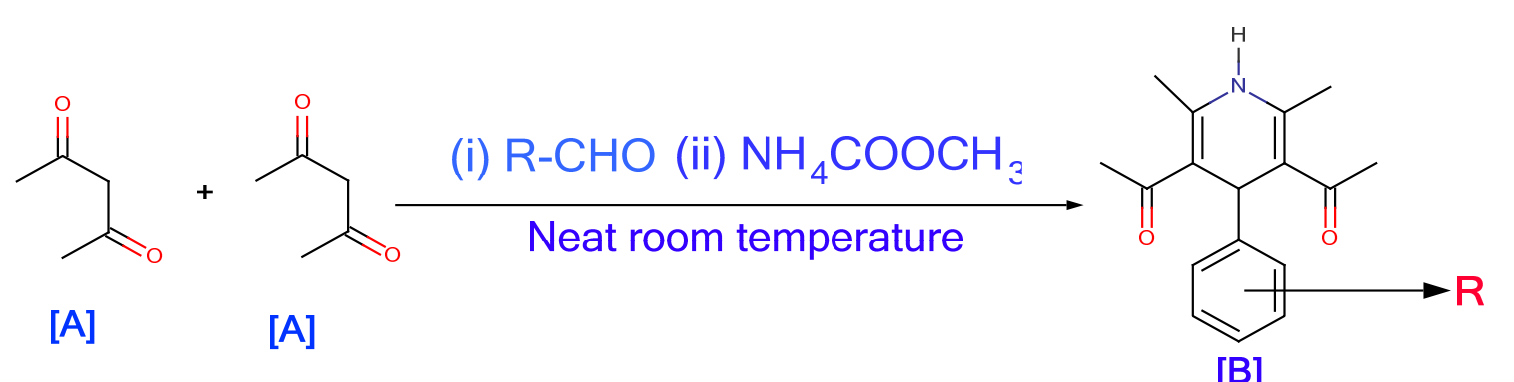

Scheme 2 Synthesis of target compounds

$[\mathrm{A}]=$ Acetyl acetone.

$[\mathrm{B}]=$ Product (1, 4-dihydropyridine derivatives) - B1, B2, B3, B4, B5 and B6 etc.

\subsection{Characterization of the Synthesized Compounds}

Compound B1:

1 - [5-acetyl-4 (4-chloro phenyl)-2, 6-dimethyl-1, 4-dihydroxypyridine-3-yl] ethan-1-one. Molecular formula: $\mathrm{C}_{17} \mathrm{H}_{18} \mathrm{ClNO}_{2}$, Molecular weight: 303.102, m .p: $180-184{ }^{\circ} \mathrm{C}$, yield: $85.2 \%$. IR ( $\left.\mathrm{KBr}\right) \mathrm{cm}^{-1}: 3334$ (-NH str), 3078 (Ar-C-H), 2924 (C-H Aliph-C-H str), $1695(\mathrm{C}=\mathrm{O}), 1582(\mathrm{C}=\mathrm{C}), \mathrm{C}-\mathrm{C}(773), 1089(\mathrm{C}-\mathrm{N}), 789$ (C-Cl). ${ }^{1} \mathrm{H}-\mathrm{NMR}\left(\mathrm{CDCl}_{3}\right): \delta 2.02\left(\mathrm{~s}, 3 \mathrm{H}, \mathrm{CH}_{3}\right), 2.9(\mathrm{~s}$, $\left.3 \mathrm{H}, \mathrm{CH}_{3}\right), 2.24$ (s, $\left.3 \mathrm{H}, \mathrm{COCH}_{3}\right), 2.44$ (s, $\left.3 \mathrm{H}, \mathrm{COCH}_{3}\right)$, 4.80 (s, 1H, CH), 7.18-8.82 (m, 7.18- 8.82-m, 4H, Ar-CH), 10.14 (s, 1H, NH). MS: m/z value-303.783. $(\mathrm{M})^{+}$Ion peak.

Compound B2:
1 - [5-acetyl-4 (4-fluro phenyl)-2,6-dimethyl-1, 4-dihydroxypyridine-3-yl] ethan-1-one. Molecular formula: $\mathrm{C}_{17} \mathrm{H}_{18} \mathrm{FNO}_{2}$, Molecular weight: 287.132, m .p: $175-179{ }^{\circ} \mathrm{C}$, yield: $73.4 \%$. IR (KBr) $\mathrm{cm}^{-1}: 3333$ (-NH str), 3079 (Ar-C-H), 2923 (C-H Aliph-C-H str), $1695(\mathrm{C}=\mathrm{O}), 1580(\mathrm{C}=\mathrm{C}), \mathrm{C}-\mathrm{C}(775), 1088(\mathrm{C}-\mathrm{N}), 688$ (C-Cl). ${ }^{1} \mathrm{H}-\mathrm{NMR}\left(\mathrm{CDCl}_{3}\right): \delta 2.01$ (s, 3H, $\left.\mathrm{CH}_{3}\right), 2.7$ (s, $\left.3 \mathrm{H}, \mathrm{CH}_{3}\right), 2.23\left(\mathrm{~s}, 3 \mathrm{H}, \mathrm{COCH}_{3}\right), 2.42\left(\mathrm{~s}, 3 \mathrm{H}, \mathrm{COCH}_{3}\right)$, 4.81 (s, $1 \mathrm{H}, \mathrm{CH}), 7.19-8.83$ (m, 7.19- 8.84-m, $4 \mathrm{H}$, Ar-CH), 10.13 (s, 1H, NH). MS: m/z value-287.32. (M)+ Ion peak.

Compound B3:

1 - [5-acetyl-4 (4-bromo phenyl)-2, 6-dimethyl-1, 4-dihydroxypyridine-3-yl] ethan-1-one. Molecular 
formula: $\mathrm{C}_{17} \mathrm{H}_{18} \mathrm{BrNO}_{2}$, Molecular weight: 347.052, m.p: $179-183{ }^{\circ} \mathrm{C}$, yield: $69.9 \%$. IR $(\mathrm{KBr}) \mathrm{cm}^{-1}: 3334$ (-NH str), 3070 (Ar-C-H), 2926 (C-H Aliph-C-H str), $1698(\mathrm{C}=\mathrm{O}), 1581(\mathrm{C}=\mathrm{C}), \mathrm{C}-\mathrm{C}(773), 1087(\mathrm{C}-\mathrm{N}), 682$ (C-Cl). ${ }^{1} \mathrm{H}-\mathrm{NMR}\left(\mathrm{CDCl}_{3}\right): \delta 2.03\left(\mathrm{~s}, 3 \mathrm{H}, \mathrm{CH}_{3}\right), 2.9(\mathrm{~s}$, $\left.3 \mathrm{H}, \mathrm{CH}_{3}\right), 2.22\left(\mathrm{~s}, 3 \mathrm{H}, \mathrm{COCH}_{3}\right), 2.44\left(\mathrm{~s}, 3 \mathrm{H}, \mathrm{COCH}_{3}\right)$, 4.80 (s, 1H, CH), 7.19-8.84 (m, 7.19- 8.84-m, 4H, Ar-CH), 10.11 (s, 1H, NH). MS: m/z value-348.234 $(\mathrm{M}+1)$ Ion peak.

Compound B4:

1 - [5-acetyl-4 (4-nitro phenyl)-2, 6-dimethyl-1, 4-dihydroxypyridine-3-yl] ethan-1-one. Molecular formula: $\mathrm{C}_{17} \mathrm{H}_{18} \mathrm{~N}_{2} \mathrm{O}_{4}$, Molecular weight: 314.12 , m.p: 145-147 ${ }^{\circ} \mathrm{C}$, yield: $78.2 \%$. IR (KBr) cm ${ }^{-1}: 3333$ (-NH str), 3078 (Ar-C-H), 2925 (C-H Aliph-C-H str), 1696 $(\mathrm{C}=\mathrm{O}), 1582(\mathrm{C}=\mathrm{C}), \mathrm{C}-\mathrm{C}(771), 1088(\mathrm{C}-\mathrm{N}), 1342$ $\left(\mathrm{NO}_{2}\right.$ grp). ${ }^{1} \mathrm{H}-\mathrm{NMR}\left(\mathrm{CDCl}_{3}\right): \delta 2.01\left(\mathrm{~s}, 3 \mathrm{H}, \mathrm{CH}_{3}\right), 2.10$ $\left(\mathrm{s}, 3 \mathrm{H}, \mathrm{CH}_{3}\right), 2.24\left(\mathrm{~s}, 3 \mathrm{H}, \mathrm{COCH}_{3}\right), 2.44(\mathrm{~s}, 3 \mathrm{H}$, $\left.\mathrm{COCH}_{3}\right), 4.81(\mathrm{~s}, 1 \mathrm{H}, \mathrm{CH}), 7.19-8.83$ (m, 7.19- 8.83-m, $4 \mathrm{H}, \mathrm{Ar}-\mathrm{CH}), 10.15$ (s, $1 \mathrm{H}, \mathrm{NH})$. MS: $\mathrm{m} / \mathrm{z}$ value-314.33 (M)+ Ion peak.

\section{Compound B5:}

1- [5-acetyl-4 (4-Hydroxy phenyl)-2, 6-dimethyl-1,4-dihydroxypyridine-3-yl] ethan-1-one. Molecular formula: $\mathrm{C}_{17} \mathrm{H}_{19} \mathrm{NO}_{3}$, Molecular weight: 285.136, m .p: $90-94{ }^{\circ} \mathrm{C}$, yield: $81.3 \%$. IR (KBr) cm ${ }^{-1}$ : 3334 (-NH str), 3078 (Ar-C-H), 2924 (C-H Aliph-C-H str), $1695(\mathrm{C}=\mathrm{O}), 1582(\mathrm{C}=\mathrm{C}), \mathrm{C}-\mathrm{C}(773), 1089(\mathrm{C}-\mathrm{N})$, 789 (C-Cl). ${ }^{1} \mathrm{H}-\mathrm{NMR}\left(\mathrm{CDCl}_{3}\right): \delta 2.19$ (s, 3H, $\left.\mathrm{CH}_{3}\right), 2.9$ (s, 3H, $\left.\mathrm{CH}_{3}\right), 2.22\left(\mathrm{~s}, 3 \mathrm{H}, \mathrm{COCH}_{3}\right), 2.43(\mathrm{~s}, 3 \mathrm{H}$, $\mathrm{COCH}_{3}$ ), 3.97 (s, 4H, ), 7.01-7.43 (4H, Ar-CH), 10.14 (s, $1 \mathrm{H}, \mathrm{NH})$. MS: $\mathrm{m} / \mathrm{z}$ value-285.3 $(\mathrm{M})^{+}$Ion peak.

Compound B6:

1-[5-acetyl-4 (4-methoxy phenyl)-2, 6-dimethyl-1, 4-dihydroxypyridine-3-yl] ethan-1-one. Molecular formula: $\mathrm{C}_{18} \mathrm{H}_{21} \mathrm{NO}_{3}$, Molecular weight: 299.15, m .p: 102-105 ${ }^{\circ} \mathrm{C}$, yield: $77.2 \%$. IR ( $\left.\mathrm{KBr}\right) \mathrm{cm}^{-1}: 3433$ (-NH str), 2992 (Ar-C-H), 2961 (C-H Aliph-C-H str), 1629 $\left(\mathrm{C}=\mathrm{O}, \mathrm{COCH}_{3}\right), 1574(\mathrm{C}=\mathrm{C}), \mathrm{C}-\mathrm{C}(794), 1034(\mathrm{C}-\mathrm{N})$. ${ }^{1} \mathrm{H}-\mathrm{NMR}\left(\mathrm{CDCl}_{3}\right): \delta 1.93\left(\mathrm{~s}, 3 \mathrm{H}, \mathrm{CH}_{3}\right), 1.98(\mathrm{~s}, 3 \mathrm{H}$, $\left.\mathrm{CH}_{3}\right), 2.73$ (s, $\left.3 \mathrm{H}, \mathrm{COCH}_{3}\right), 2.78\left(\mathrm{~s}, 3 \mathrm{H}, \mathrm{COCH}_{3}\right), 3.97$ (s, 3H, $\left.\mathrm{OCH}_{3}\right), 4.62(\mathrm{~s}, 1 \mathrm{H}, \mathrm{CH})$ 7.04-7.43 (m, 3H, Ar-CH), 10.14 (s, 1H, NH). MS: m/z value-299.36 $(\mathrm{M})^{+}$Ion peak.

\subsection{Evaluation of Acute Toxicity [14]}

In the present study the acute oral toxicity of the synthesized compounds were performed by acute toxic class method. In this method the toxicity of the synthesized compound was planned to test using step wise procedure, each step using three Wister rats. The rats were fasted prior to dosing (food but not water should be withheld) for three to four hrs. Following the period of fasting the animals were weighed and the compound was administered orally at a dose of 2,000 $\mathrm{mg} / \mathrm{Kg}$ b.w. Animals were observed individually after dosing at least once during the first $30 \mathrm{~min}$; periodically the surveillance was carried out for the first $24 \mathrm{hrs}$ with special attention given during the first $4 \mathrm{hrs}$ and daily thereafter, for a total of 14 days.

\subsection{Experimental Protocol for Hepatoprotetive Activity} [15]

A total of 30 rats were taken and divided into 5 groups of 6 rats each

(A) Group I: Normal Control Group (only the vehicle ( $1 \mathrm{~mL} / \mathrm{kg} /$ day of $1 \% \mathrm{CMC}$; p.o.)

(B) Group II: Negative Control CCl4 $1 \mathrm{~mL} / \mathrm{kg}(1: 1$ of $\mathrm{CCl}_{4}$ in olive oil) i.p.

(C) Group III: Positive Control/Standard Group $\left[\mathrm{CCl}_{4} 1 \mathrm{~mL} / \mathrm{kg}\left(1: 1\right.\right.$ of $\mathrm{CCl}_{4}$ in olive oil) i.p. + Standard Silymarin $100 \mathrm{mg} / \mathrm{kg}$ orally (p.o.) for 7 days]

Treatment Groups

(D) Group IV: High Dose Group [CCl $1 \mathrm{~mL} / \mathrm{kg}$ (1:1 of $\mathrm{CCl}_{4}$ in olive oil) i.p + Synthesized compounds (500 $\mathrm{mg} / \mathrm{kg}$ b. w., p.o.)]

(E) Group V: Low Dose Group [ $\mathrm{CCl}_{4} 1 \mathrm{~mL} / \mathrm{kg}(1: 1$ of $\mathrm{CCl}_{4}$ in olive oil) i.p Synthesized compounds (250 $\mathrm{mg} / \mathrm{kg} \mathrm{b}$. w., p.o.)]. Treatment was given daily for seven days orally.

Collection of blood: On the 8th day, blood was collected by retro orbital puncture, under mild ether 
anesthesia after $8 \mathrm{hr}$ fasting. Blood samples were centrifuged at $3000 \mathrm{rpm}$ for 20 mins. Serum was separated and stored at $-200{ }^{\circ} \mathrm{C}$ until biochemical estimations.

\subsection{Biochemical Analysis}

The Serum samples were analyzed for

(1)Alanine Aminotransferase (ALT) (SGPT)

(2)Aspartate Aminotransferase (AST) (SGOT)

(3)Alkaline Phosphate (ALP)

(4)Serum Bilirubin

\subsection{Histopathological Analysis}

The liver tissue was dissected out and fixed in $10 \%$ formalin solution. It was then dehydrated in ethanol (50\%-100\%), cleared in xylene and embedded in paraffin wax. Afterwards thick sections (5-6 mm) were made and then stained with hematoxylin and eosin dye for photo microscopic observation. The whole biochemical and histopathological analysis was carried out at V.H.S Hospital in Chennai.

\section{Results and Discussion}

\subsection{Chemistry}

The synthesis of target compounds 1-[5-acetyl-4 (4-substituted phenyl)-2,6-dimethyl-1,4-dihydroxypyridine-3-yl]-eth an-1-one were carried out by reacting acetyl acetone with various aromatic aldehydes in the presence of ammonium acetate. The synthesized compounds were characterized by IR, NMR, and Mass spectroscopy and proposed the structure by spectral data. The purity of the synthesized compounds was ascertained by TLC and spectral analysis.

\subsection{Acute Oral Toxicity Studies}

In this study the acute oral toxicity was evaluated by "Acute toxic class methods (OECD guideline-423)". The extract was administered orally at a dose of 2000 $\mathrm{mg} / \mathrm{Kg}$ b. wt. During the surveillance period no significant toxicity occurred along with minute non-considerable behavioral changes. After a statistical analysis by trial and error, the significant doses were chosen at $250 \mathrm{mg} / \mathrm{kg}$ b. wt p. o (LD) and $500 \mathrm{mg} / \mathrm{kg} \mathrm{b}$. wt p. o. (HD) considerably

\subsection{Hepatoprotective Activity}

Statistical analysis

The data were expressed as mean \pm SD. Statistical differences at $* P<0.05$ between the groups were analyzed by one-way ANOVA followed by Dunnett's Multiple Comparison Test using Graph Pad Prism 5.04 Instate software package. The data's were compared with group 2, i.e., Negative Control group.

The present study displayed that synthesized compounds were possessed a significant hepatoprotective activity which was at least partially attributed to its pronounced antioxidant capacity. The declining of plasma enzyme level is a prognostic status of the hepatoprotective action of the drug. Protection of hepatic damage caused by carbon tetrachloride administration was observed by recording SGOT, SGPT, SALP and Serum bilirubin levels in different groups [16].The transport function of the hepatocytes is disturbed in hepatic injury, causing the leakage of enzymes due to altered membrane permeability [17]. Although both the doses ( 250 and $500 \mathrm{mg} / \mathrm{kg} \mathrm{b}$. w.) of synthesized compounds executed hepatoprotective activity, the higher dose (500 $\mathrm{mg} / \mathrm{kg}$ b.w.) is more effective and more significant (Tables 1-4, Figs. 1-4).

\subsection{Biochemical Analysis}

The effects of synthesized compounds on liver marker enzymes and serum bilirubin content are displayed in Table 5. The data exhibited that Normal Control Group demonstrated a normal range of AST, $\mathrm{ALT}$, and bilirubin levels while the $\mathrm{CCl}_{4}$-treated group showed elevated levels of AST, ALT, and bilirubin, thus confirming that $\mathrm{CCl}_{4}$ causes hepatocellular degeneration at higher doses. The elevation of cytoplasmic AST and ALT is considered an indicator for the release of enzymes from disrupted liver cells. 
Table 1 Comparison of total bilirubin level.

\begin{tabular}{lcl}
\hline Dunnett's Multiple Comparison Test Significant? & Summary \\
\hline Control vs. normal & Yes & $* * *$ \\
Control vs. low dose & No & $\mathrm{ns}$ \\
Control vs. high dose & Yes & $* *$ \\
Control vs. Standard & Yes & $* * *$ \\
\hline
\end{tabular}

Table 3 Comparison of ALT (SGPT) level.

\begin{tabular}{lcl}
\hline Dunnett's Multiple Comparison Test Significant? & Summary \\
\hline Control vs. normal & Yes & $* * *$ \\
Control vs. low dose & Yes & $*$ \\
Control vs. high hose & Yes & $* * *$ \\
Control vs. standard & Yes & $* * *$ \\
\hline
\end{tabular}

Table 2 Comparison of SGOT (AST) level.

\begin{tabular}{lcl}
\hline Dunnett's Multiple Comparison Test Significant? & Summary \\
\hline Control vs. normal & Yes & $* * *$ \\
Control vs. low dose & No & ns \\
Control vs. high dose & Yes & $* * *$ \\
Control vs. standard & Yes & $* * *$ \\
\hline
\end{tabular}

Table 4 Comparison of ALP (SALP) level.

\begin{tabular}{lcl}
\hline Dunnett's Multiple Comparison Test Significant? & Summary \\
\hline Control vs. normal & Yes & $* * *$ \\
Control vs. low dose & Yes & $*$ \\
Control vs. high dose & Yes & $* * *$ \\
Control vs. standard & Yes & $* * *$ \\
\hline
\end{tabular}

Table 5 for the assessment of Biochemical parameters.

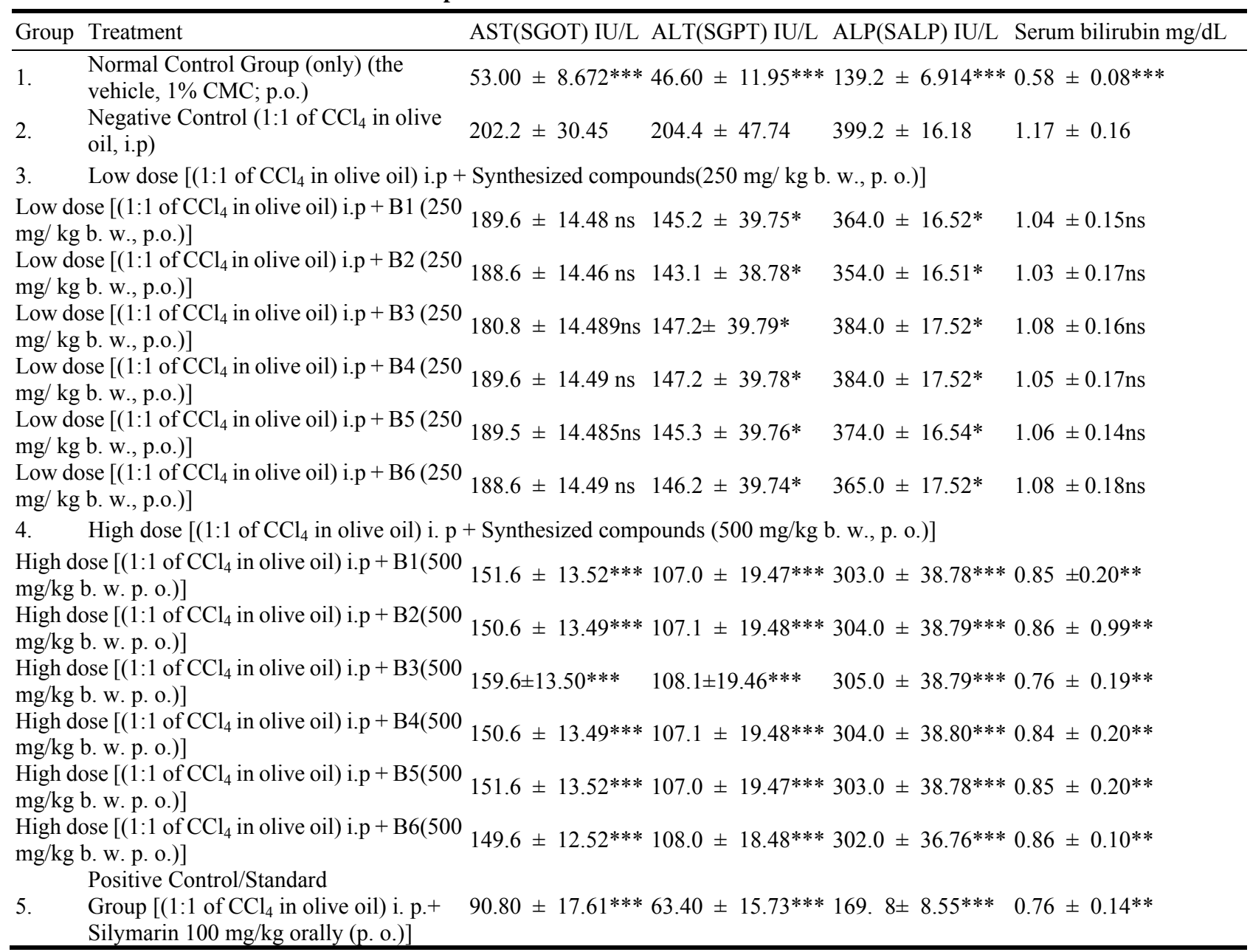

Data are expressed as mean \pm SD $(n=6)$. One-way ANOVA followed by Dunnett's Multiple Comparison Test $(* P<0.05)$ compared with group $2 ;($ ns $=$ non significant $)$. 
Bilirubin concentration has been used to evaluate chemically induced hepatic injury. Results displayed in Table 5 indicate that the elevated levels of SGOT, SGPT, ALP and serum bilirubin due to $\mathrm{CCl}_{4}$ intoxication were reduced significantly $\left({ }^{*} P<0.05\right)$ in rats, after treatment with synthesized compounds. Treatment with a synthesized compound at a dose of $250 \mathrm{mg} / \mathrm{kg}$ b.w. decreased the SGOT, SGPT, ALP, Serum Bilirubin levels by $6.23 \%$ ns(non significantly), $28.96,8.81$, and $11.11 \% \mathrm{~ns}$ (non significantly) respectively, while a higher dose of $500 \mathrm{mg} / \mathrm{kg} \mathrm{b}$. wt. was more effective, causing a reduction of $25.02 \%$, $47.65 \%, 24.09 \%$ and $27.35 \%$. Silymarin used as standard drug showed a reduction of $55.09 \%, 68.98 \%$, $57.46 \%$ and $35.04 \%$ receiving $\mathrm{CCl}_{4}$ alone. So depending upon the data of Table 5 it was confirmed that the biochemical parameters of the group treated with compounds were significantly lower than the $\mathrm{CCl}_{4}$-treated group. Moreover the treatment with the synthesized compounds significantly reduced the previously raised levels of AST, ALT, ALP and bilirubin in hepatotoxic rats.

\subsection{Histopathology Analysis}

The results of light microscopy examination of the transverse section of control, $\mathrm{CCl}_{4}$-treated and treated with synthesized compounds rat livers were represented in Figs 5, 6. It was revealed that the liver section of animals treated with $\mathrm{CCl}_{4}$ showed a high degree of damage characterized by cell vacuolation, pyknotic and degenerated nuclei and wall of bile capillaries. The normal architecture of the liver was lost. The intralobular vein was badly damaged with wide spaces at some sinusoids. Liver sections of these rats indicated necrosis, ballooning and degeneration in hepatic plates and loss of cellular boundaries. There was also a heavy accumulation of neutrophils surrounding the portal vein. These neutrophils act as an indicator of the occurrence of cell damage as they are absent in normal healthy tissues. The hepatocytes are disrupted and sinusoids are damaged as well.

Overall, a healthy set of cells can be observed, bile ducts and portal triad is prominent, no necrosis (Fig. 5), reveals the liver section of the animals treated with synthesized compound ( $250 \mathrm{mg} / \mathrm{kg} \mathrm{b}$. w. $)+\mathrm{CCl}_{4}$, the nuclei are not very clear as in normal hepatocytes; however, when compared to the $\mathrm{CCl}_{4}$ damaged group, the number of hepatocytes with normal nucleus was considerably more. The endothelium is disrupted in places. Pyknotic nucleus and vacuolation in cytoplasm are observed to be low, as compared to the $\mathrm{CCl}_{4}$ group. But very less effective and has demonstrated very less recovery, with obscure central triad and infiltration of neutrophils around central vein, degraded fatty change,

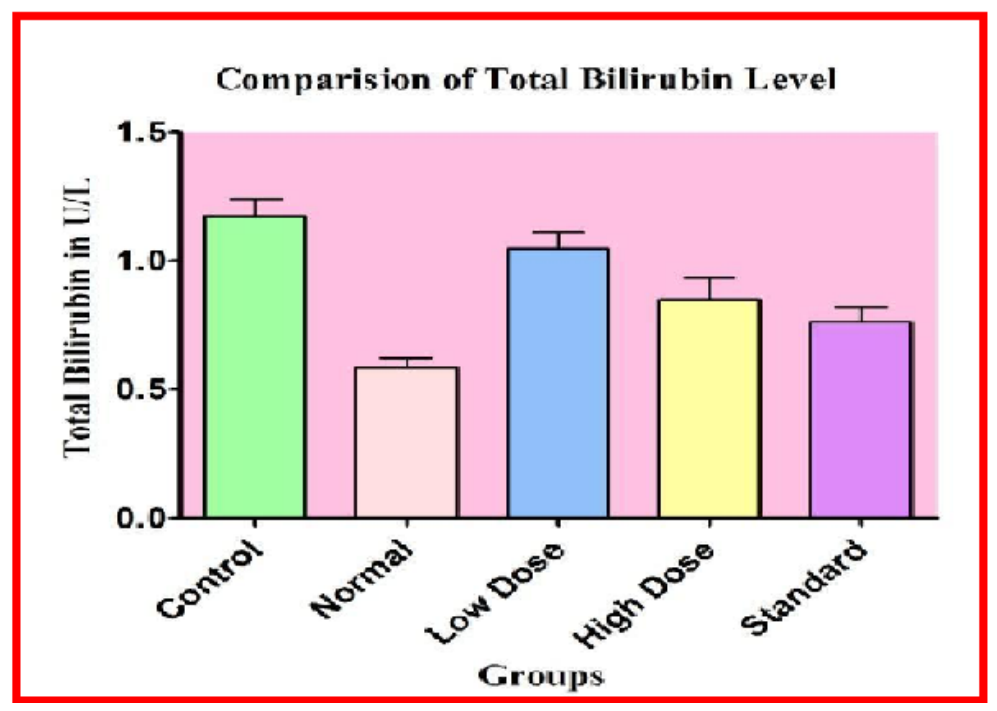

Fig. 1 Comparison of bilirubin level total. 
Synthetic novel 1, 4- dihydropyridine derivatives act as Potential

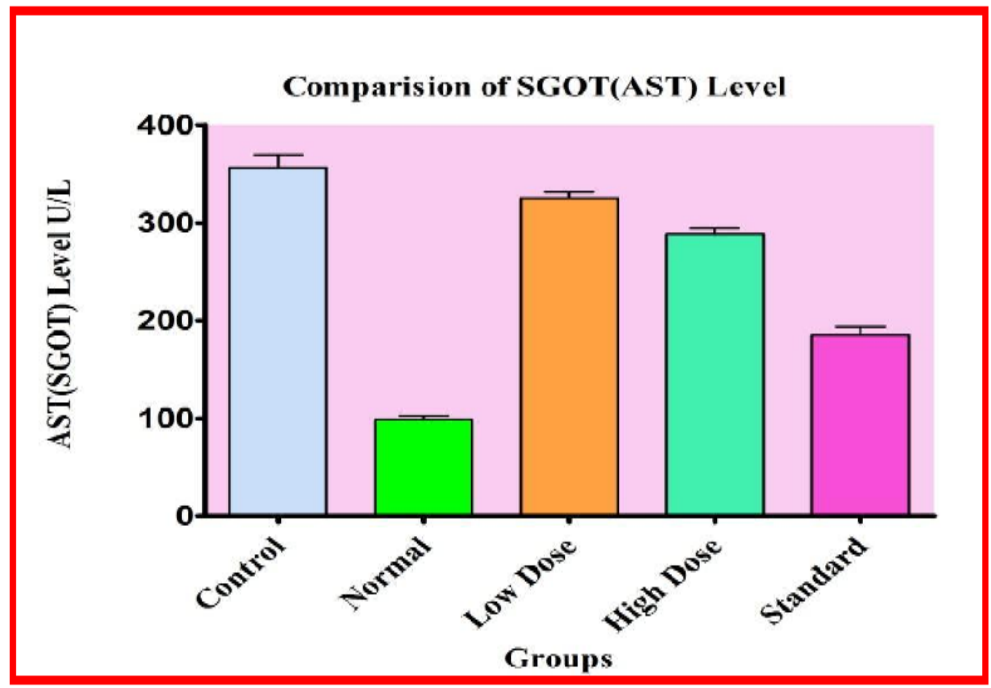

Fig. 2 Comparison of AST (SGOT) level.

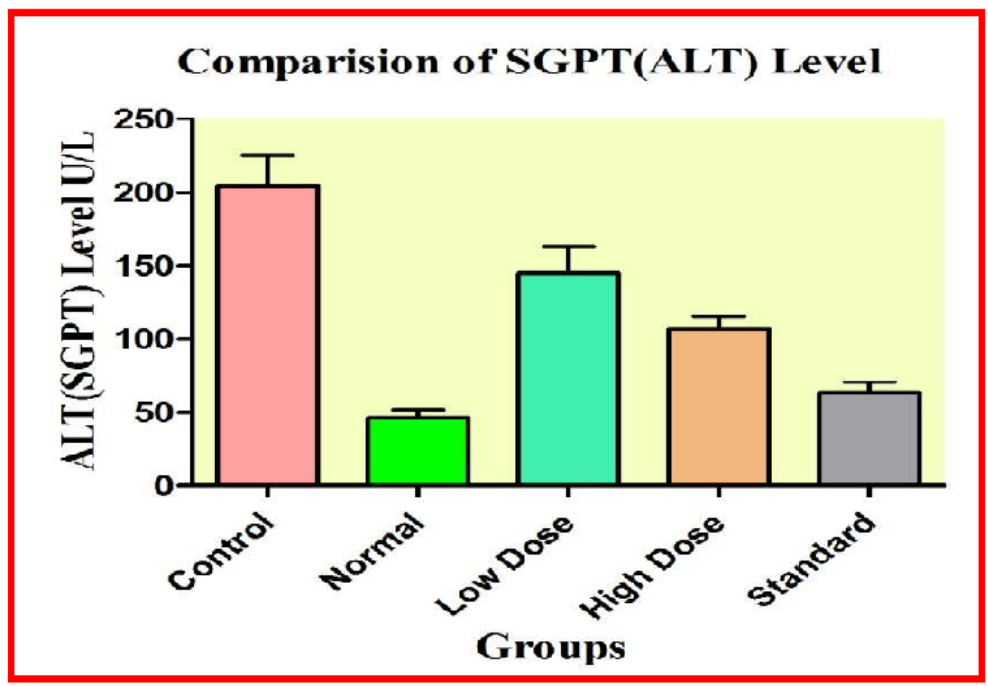

Fig. 3 Comparison of ALT (SGPT) level.

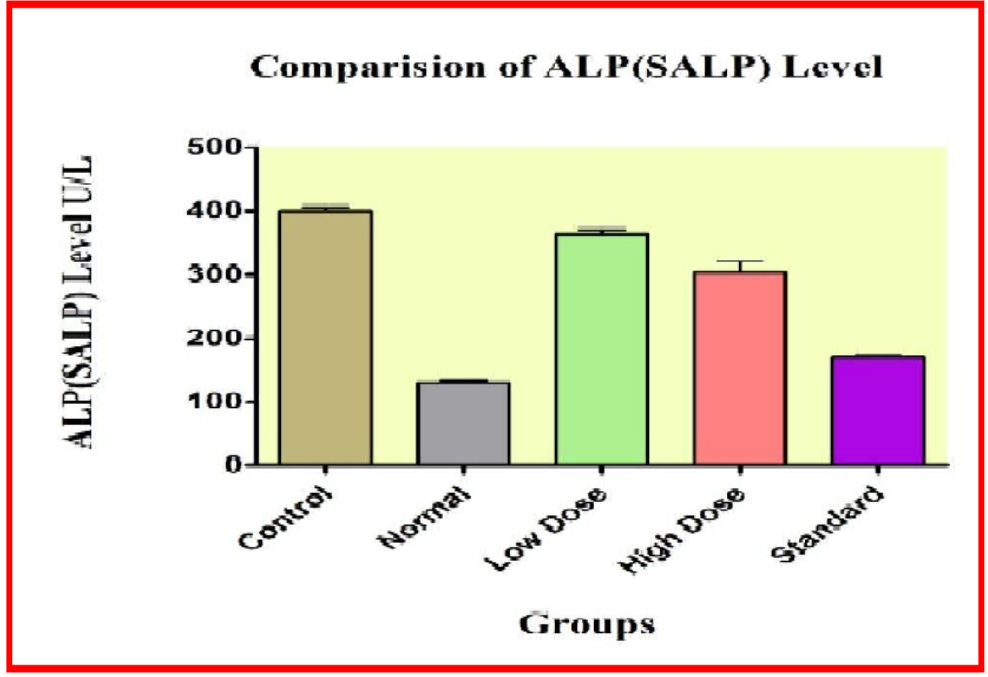

Fig. 4 Comparison of ALP (SALP) level. 


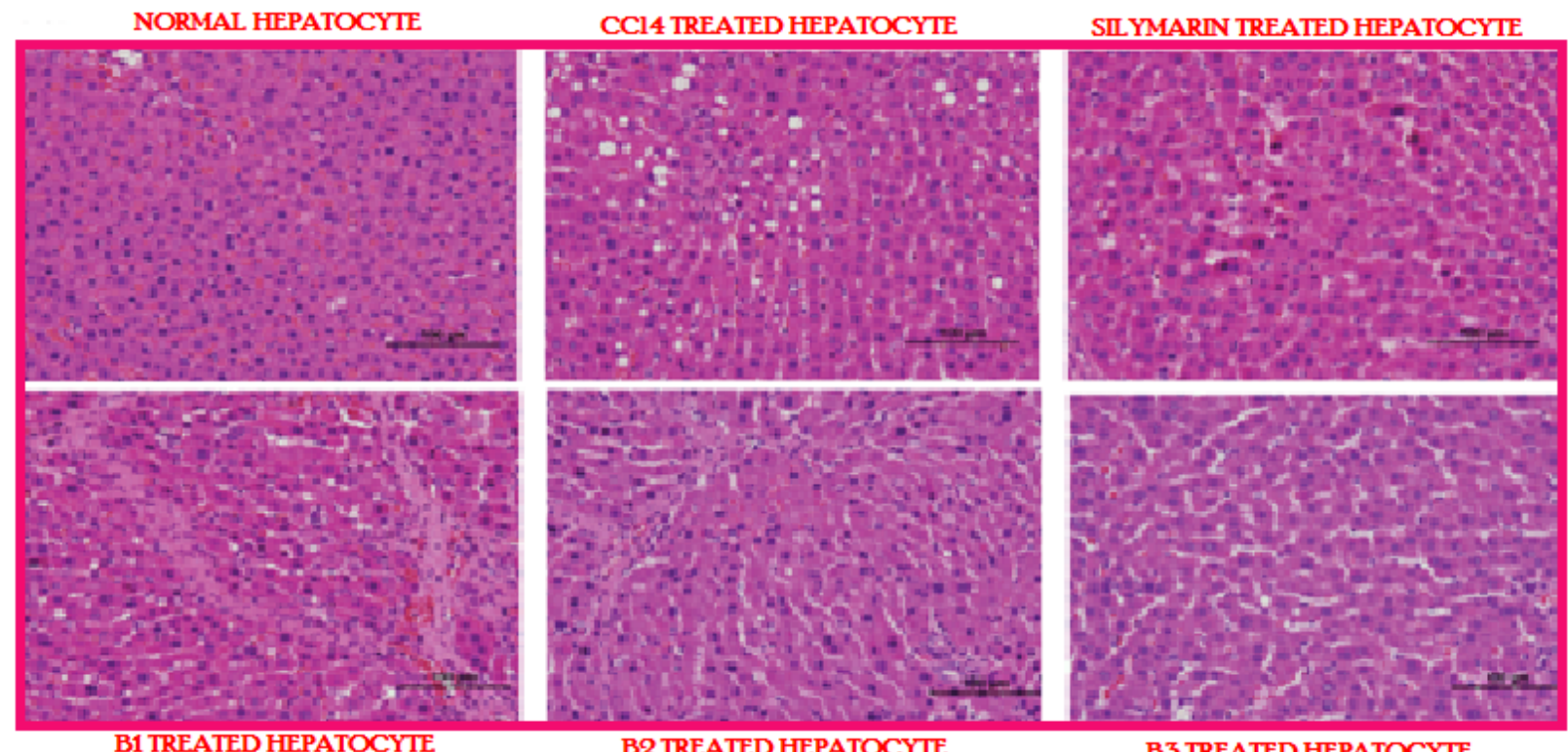

Fig. 5 Histopathological examination of hepatocytes treated with synthesized compounds at low doses ( $250 \mathrm{mg} / \mathrm{kg}$. b.w.).

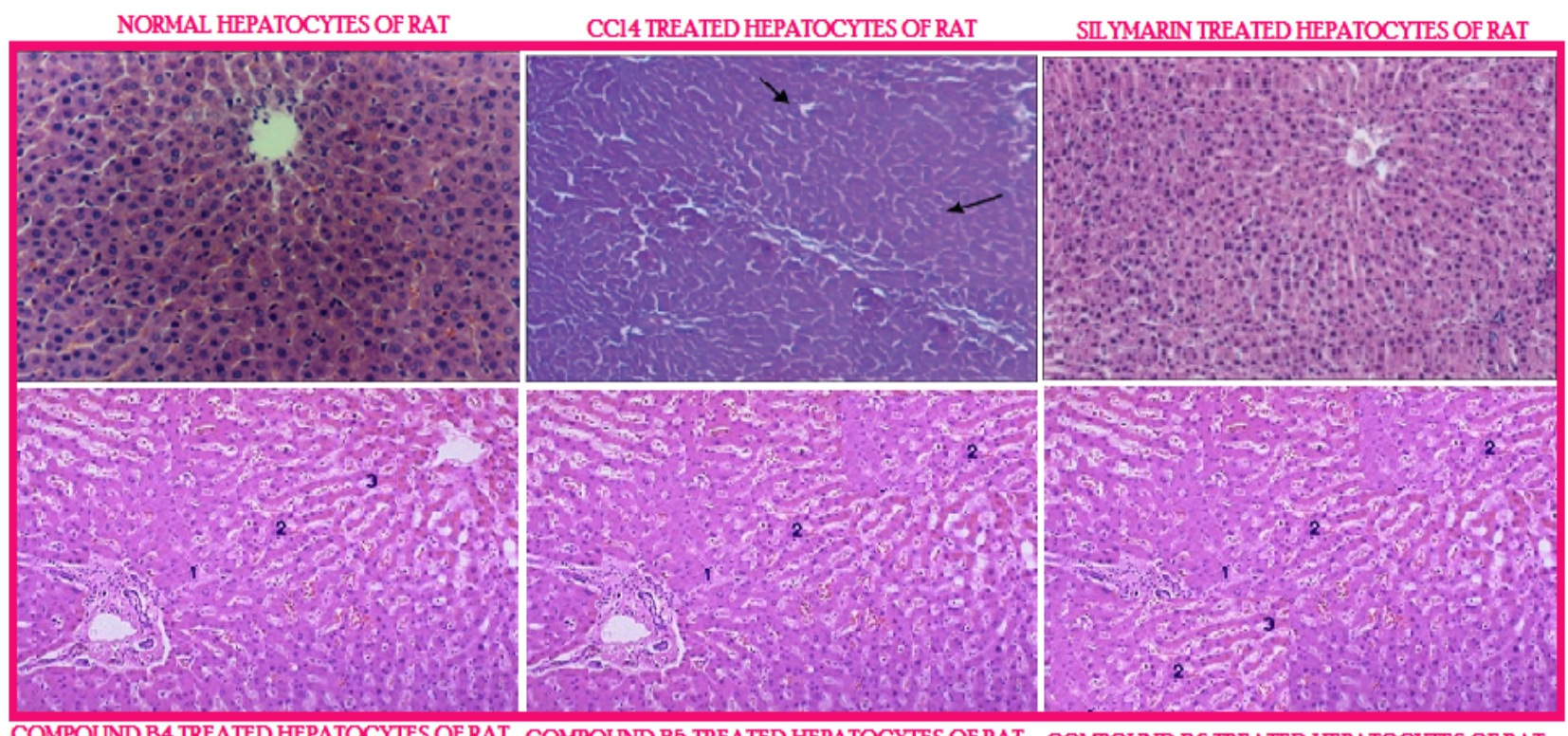

C 6 .

and necrosis and focal necrosis (dilatation), loss of cellular boundaries .

The hepatic cells of rats treated with the synthesized compound (500 mg/kg b.w.) and intoxicated with $\mathrm{CCl}_{4}$ were radially arranged. The vacuolation was present, similar to that of normal. The recovery was comparable to that with Silymarin [Fig. 6], a standard hepatoprotective agent. Liver section of rats treated $\mathrm{CCl}_{4}$ and $500 \mathrm{mg} / \mathrm{kg}$ of synthesized compound demonstrated minimal inflammatory cellular infiltration around central vein, absence of necrosis, neutrophil cascades forming fibrous network, considerable protection and large septa of connective tissue flowing together and penetrating into the parenchyma, normal liver architecture.

\section{Conclusions}

In conclusion, we report here a series of novel 
1,4-dihydropyridine derivatives prepared by reacting acetyl acetone with various aromatic aldehydes in the presence of ammonium acetate and their ability to regenerate the hepatocytes in vivo. The hepatoprotective activity of the synthesized compounds (B1-B6) can be considered very well with regards to the standard drug silymarin.

\section{References}

[1] "1, 4-dihydropyridine - Compound Summary". Pubchem Compound. USA: National Center for Biotechnology Information. 27 March 2005. Identification and Related Records. Retrieved 1 November 2011.

[2] Hantzsch, A. 1881. "Condensationprodukteaus Aldehydammoniak and Ketonartigen Verbindungen." Chemische Berichte $14 \quad$ (2): $1637-8$. doi:10.1002/cber.18810140214.

[3] Xia, J. J., and Wang, G. W. 2005. "One-Pot Synthesis and Aromatization of 1, 4-Dihydropyridines in Refluxing Water." Synthesis $2005 \quad$ (14): 2379-83. Doi:10.1055/s-2005-870022.

[4] Van den Eynde, J. J., and Mayence, A. 2003. "Synthesis and Aromatization of Hantzsch 1,4-Dihydropyridines under Microwave Irradiation. An Overview." Molecules 8 (4): 381-91. Doi: 10.3390/80400381.

[5] Olson, K. 2011. "40. Calcium Channel Antagonists." In Poisoning \& drug overdose, 6th ed. McGraw-Hill Medical. ISBN 0071668330.

[6] "calcium channel blocker" at Dorland's Medical Dictionary.

[7] Nelson, M. 2010. "Drug treatment of Elevated Blood Pressure." Australian Prescriber 33 (4): 108-12.

[8] Felizola, S. J. A., Maekawa, T., Nakamura, Y., Satoh, F.,
Ono, Y., Kikuchi, K., Aritomi, S., Ikeda, K., Yoshimura, M., Tojo, K., and Sasano, H. 2014. "Voltage-gated Calcium Channels in the Human Adrenal and Primary Aldosteronism.”. J. Steroid Biochem. Mol. Biol. 144 (part B): 410-6. doi:10.1016/j.jsbmb.2014.08.012. PMID 25151951.

[9] Remuzzi, G., Scheppati, A., and Ruggenenti, P. 2002. "Clinical Practice. Nephropathy in Patients with Type 2 Diabetes." New England Journal of Medicine 346 (15): 1145-51. doi:10.1056/NEJMcp011773. PMID 11948275.

[10] Godfraid, T., Miller, R., and Wibo, M. 1986. "Calcium antagonist and Calcium Entry Blockade of 1, 4-dihydropyridine." Pharmacology Review 38: 321-416.

[11] Rudong, S., Howelett, E., and Knaus, E. 2002. "Synthesis, Calcium Channel Agonist-antagonist Modulation Activities, Nitric Oxide Release and Voltage-clamp Studies of 2-Nitrooxyethyl 1,4-Dihydro-2,6-Dimethyl -3-Nitro-4-(2-Trifluro Methyl Phenyl) Pyridine-5-Carboxylate Enantiomers." Journal of Medicinal Chemistry 45 (4): 955-61.

[12] Maitland, J. Jr. 2000. Text book of Organic Chemistry. 2nd ed. London: W.W Norton \& Company, 1241-2.

[13] Norman, R. O. C, and Coxon, J. M. 2009. Principal of Organic Synthesis. 3rd ed. C.R.C Press, 699-702.

[14] “OECD guidelines-423" for testing of chemicals, 2001, pp 1-14

[15] Garrat, D. C. 1964. The Quantitative Analysis of Drugs. Chapman and Hall, 456.

[16] Higa, L. 2000. "Evaluation of Jaundice.” In liver Disease Diagnosis and Management, edited by Bacon, B., and Di Bisceglie, A. New York: Churchill Livingston, 318-28.

[17] Zimmerman, H. 1982. "Chemical Hepatic Injury and Its Detection.” In Toxicology of the liver, edited by Plaa, G., and Hewitt, W. New York: Reven Press, 11-45. 